\title{
РАЗРАБОТКА МЕРОПРИЯТИЙ ПО РЕАБИЛИТАЦИИ ПАЦИЕНТОВ С ПОВРЕЖДЕНИЕМ НИЖНЕГО АЛЬВЕОЛЯРНОГО НЕРВА
}

\author{
И. С. Копецкий${ }^{1}$, Д. А. Еремин ${ }^{1}$, Н. В. Полунина², В. С. Полунин ${ }^{2}$, Г. Н. Буслаева², А. К. Хетагурова ${ }^{2}$ \\ Кафедра терапевтической стоматологии, стоматологический факультет \\ Российский национальный исследовательский медицинский университет им. Н. И. Пирогова, Москва \\ 2 Кафедра общественного здоровья и здравоохранения, экономики здравоохранения, педиатрический факультет \\ Российский национальный исследовательский медицинский университет им. Н. И. Пирогова, Москва,
}

\begin{abstract}
Среди повреждений костей лицевого скелета переломы нижней челюсти встречаются часто. Наиболее распространенной локализацией переломов нижней челюсти при которых происходит травма нижнего альвеолярного нерва (НАН), являются угол и тело, в толще которых проходит НАН. Пациенты челюстно-лицевых стационаров имеют низкую медицинскую и социальную грамотность, поэтому целью исследования явилось повышение эффективности лечения больных с переломами нижней челюсти, сопровождающимися травмой НАН, путем внедрения нового комплекса фармакологических препаратов - Мексикора и Комбилипена, ранее не использовавшихся в челюстнолицевой хирургии, и медико-социальных мероприятий, направленных на формирование мотивации к ведению здорового образа жизни у пациентов.
\end{abstract}

Ключевые слова: перелом нижней челюсти, повреждение нижнего альвеолярного нерва, социальная реабилитация, здоровый образ жизни, Мексикор, Комбилипен

$\bigotimes$ Для корреспонденции: Полунин Валерий Сократович

ул. Островитянова, д. 1, г. Москва, 117997; lunapol@yandex.ru

Статья получена: 14.11.2017 Статья принята к печати: 16.02.2018

DOI: 10.24075/vrgmu.2018.007

\section{REHABILITATION OF PATIENTS WITH INFERIOR ALVEOLAR NERVE INJURIES}

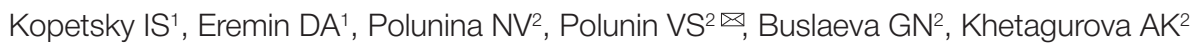

Department of Dental Therapy, Faculty of Dentistry

Pirogov Russian National Research Medical University, Moscow

2 Department of Public Health, Healthcare and Healthcare Economics, Faculty of Pediatrics, Pirogov Russian National Research Medical University, Moscow

Mandibular fractures are a common type of injuries of the facial bones. Most of them affect the angle and body of the mandible in the areas innervated by the inferior alveolar nerve (IAN). Inpatients of maxillofacial units often lack health literacy; therefore, the aim of our study was to improve the effect of treatment in patients with mandibular fractures and IAN injuries by motivating patients toward a healthy lifestyle and by pioneering the use of therapeutic agents Mexicor and Combilipen in the standard regimen.

Keywords: mandibular fracture, inferior alveolar nerve injury, rehabilitation, healthy lifestyle, Mexicor, Combilipen

Correspondence should be addressed: Valery Polunin

Ostrovityanova 1, Moscow, 117997; lunapol@yandex.ru

Received: 14.11.2017 Accepted: 16.02.2018

DOI: $10.24075 /$ brsmu.2018.007

В последние годы отмечается увеличение количества больных с травмами костей лицевого скелета, характеризующимися в основном множественными переломами и сочетанными повреждениями и полученными в результате дорожно-транспортных происшествий, противоправных действий третьих лиц, спортивных соревнований и др. [1]. Переломы нижней челюсти среди них составляют по данным зарубежных и отечественных авторов до 87\%, практически во всех случаях наблюдается повреждение нижнеальвеолярного нерва (HАН) $[2,3]$. Травма НАН происходит вследствие ушиба, растяжения, сдавления костными фрагментами нижней челюсти. В результате травмы растяжение отмечается в 70,1\%, контузия (ушиб) - в 16,8\%, неполный разрыв - в 12,5\% и полный разрыв - в 0,6\% случаев [4]. При повреждении НАН выделяют субклиническую, легкую, среднюю, среднетяжелую и тяжелую степени повреждения [5, 6]. Независимо от вида повреждения периферического нерва наблюдаются нейротрофические изменения в тканях, которые он иннервирует: нарушение процессов остеорепарации в зоне перелома, дефицит чувствительности в зоне иннервации. Во всех случаях отмечается болевой синдром, который является основным проявлением этого вида патологии [7, 8]. Коррекция нарушений здоровья у данной категории пациентов проводится в челюстно-лицевых стационарах и кабинетах реабилитации, существующих при них, после выписки из стационара. Коррекция включает хирургические мероприятия в виде иммобилизации костных фрагментов и накостного остеосинтеза при наличии выраженного смещения костных фрагментов и консервативную медикаментозную терапию [9, 10, 11, 12, 13].

Кроме того, показана необходимость проведения не только мероприятий по медицинской реабилитации у больных с переломами нижней челюсти, но и социально-психологических мероприятий, направленных на 
формирование мотивации у больных к ведению здорового образа жизни и повышение медицинской грамотности $[14,15]$.

Несвоевременная диагностика, отложенная иммобилизация или показанное оперативное лечение, неэффективная медикаментозная терапия, несоблюдение пациентом рекомендаций и отсутствие стремления $\mathrm{k}$ здоровому образу жизни способствуют возникновению необратимых изменений НАН. Такие изменения приводят к нарушению консолидации костных фрагментов, развитию воспаления, утрате чувствительности и двигательной способности мышц в зоне иннервации нерва. Все это обусловило необходимость разработки мероприятий комплексной реабилитации данной категории пациентов.

\section{ПАЦИЕНТЫ И МЕТОДЫ}

В исследовании участвовали 212 мужчин. Критерии включения: возраст от 19 до 63 лет, наличие односторонних переломов нижней челюсти, отсутствие выраженных сопутствующих заболеваний, поступление в стационар ГКБ №1 им. Н. И. Пирогова, г. Москвы в период 20112016 гг. в первые сутки от момента получения травмы. Критерии исключения: наличие выраженных сопутствующих соматических заболеваний, воспалительных явлений и множественных переломов нижней челюсти. Все пациенты, подписывали информированное согласие, дизайн исследования одобрен на заседании этического комитета РГМУ им Н.И.Пирогова, протокол №107 от 18.04.2011 г. После выписки из стационара наблюдение проводилось в кабинете реабилитации амбулаторных пациентов. В процессе лечения проводилось анкетирование с целью выявления медико-социальных характеристик пациентов, работа с психологом.

Всем больным при поступлении проводили иммобилизацию ортопедическими конструкциями, по показаниям выполняли удаление зубов из щели перелома. При подозрении на черепно-мозговую травму назначалось обследование у невролога или нейрохирурга, а также для исключения и выявления сопутствующей патологии у терапевта, травматолога, оториноларинголога. При отсутствии эффекта от двучелюстного шинирования, нарушении прикуса, выполняли операцию остеосинтеза нижней челюсти с использованием титановых пластин. Медикаментозная терапия заключалась в назначении антибактериальных препаратов (линкомицин 2,0 мл в/м 2 раза в день, цефазолин 1 г в/м 2 раза в день) для предупреждения воспалительных осложнений, анальгетиков (Диклофенак 2,0 мл в/м 2 раза в день), использовании медикаментозных средств, назначенных другими специалистами, орошения полости рта растворами антисептиков.

Пациенты были распределены на 2 группы. В контрольную группу входили 86 пациентов. Для лечения им были назначены неостигмина метилсульфат (Прозерин, Дальхимфарм, Россия) по 1 мл 0,5\%-го раствора в течение месяца, цианокобаламин по 500-1000 мкг чередовали с 5\%-м раствором тиамина хлорида по 3 мл, 15-20 инъекций, дибазол по 0,005 г внутрь в течение месяца. В основную группу входили 126 человек. В состав комплексной терапии им были назначен препараты пиридоксин + тиамин + цианокобаламин + [лидокаин] (Комбилипен, ОАО Фамстандарт - УсраВИТА, Россия) и этилметилгидроксипиридина сукцинат (Мексикор, ЭкоФармИнвест, Россия).
Этилметилгидроксипиридина сукцинат применяли в дозировке 150 мг, согласно инструкции, внутримышечно 2 раза в день в течение 14 дней. В дальнейшем препарат применялся в капсулах по 100 мг 2 раза в день в течение 21 дня.

Комбилипен применяли в ампулах по 2 мл внутримышечно 1 раз в день в течение 10 дней. В дальнейшем препарат применяли 3 раза в неделю в течение 3 недель.

Согласно классификации степени тяжести повреждения НАН (Корж А. А., 1989 г.), пациенты основной и контрольной групп были разделены на три группы: первую группу составили пациенты с легкой степенью тяжести повреждения НАН, вторую со средней степенью и в третью вошли пациенты с средне-тяжелой и тяжелой степенями.

Для определения эффективности проводимой терапии были использованы следующие методы:

1. Определение локализации и площади нарушения иннервации, для определения зон электровозбудимости кожи нижней губы и подбородка на стороне повреждения.

Для более точного определения локализации зоны гипо- и парестезии, а также для аргументированной интерпретации результатов проводимой послеоперационной терапии была спользована схема: для построения условных квадрантов на лице пациента отмечали три точки: середина расстояния от нижней губы до выступающей части подбородка - точка А, середина расстояния от угла рта до края нижней челюсти - точка В, при соединении этих точек образуется горизонталь. Точка C располагалась на середине расстояния половины нижней губы. Вертикаль, опущенная из точки С, пересекала горизонтальную линию и образовывались 1-я, 2-я, 3-я и 4-я условные зоны [16].

Определение тактильной чувствительности проводили путем раздражения кожи подбородочной области кисточкой или ватным тампоном. При помощи пальпации исследовали глубокую чувствительность указанной области.

Было проведено определение показателей электровозбудимости кожи на стороне повреждения НАН в области нижней губы и подбородка в указанных квадрантах. Данное исследование проводили в первые сутки после поступления, на 10-й день и на 32-40-й день, в момент снятия назубных шин и через 6 месяцев после травмы.

Определение показателей электровозбудимости кожи нижней губы и подбородка проводили следующим образом. Кожу в исследуемой области предварительно обрабатывали 70\%-м раствором этилового спирта для дезинфекции и улучшения электрического контакта. Электрод аппарата PARKELL Digitest 2 (Parkell, CША) прикладывали к симметричным зонам на лице в месте иннервации НАН в соответствующих квадрантах. Определяли минимальную силу тока, при которой появлялось первое ощущение у пациента (покалывание, пощипывание и т. д.), о котором он сразу сообщал врачу. Электроток подавали в импульсном режиме возрастающей силы от 0 до 160 мкА [17].

Кроме того, объективным критерием распределения на подгруппы являлись показатели электровозбудимости кожи на стороне повреждения НАН. Для стандартизации полученных результатов электровозбудимость измеряли в 3-й зоне. Показатели электровозбудимости, измеряемые у исследуемых пациентов на здоровой стороне, варьировали от 25 до 35 мкА. У пациентов с травмой легкой степени тяжести показатели электровозбудимости кожи в 
измеряемых зонах составляли от 35 до 69 мкА, у пациентов с травмой средней степени тяжести — от 70 до 129 мкА, у пациентов с травмой тяжелой степени — от 130 мкА и выше.

2. Изучение социально-гигиенических характеристик пациентов.

Более половины пациентов с переломами нижней челюсти находилось в алкогольном опьянении при поступлении в приемное отделение. Пациенты - водители транспортных средств в 29,8\% случаев находились в той или иной степени алкогольного опьянения. Результаты изучения распространенности вредных привычек показали, что 38,4\% пациентов злоупотребляют алкоголем. Было выявлено, что среди неработающих пациентов злоупотребляющих алкоголем в 2,3 раза больше (56,6\% против 24,6\%). Отмечено, что лиц с высшим образованием, злоупотребляющих алкоголем, достоверно (p < 0,05) меньше, чем пациентов, имеющих среднее или неполное среднее образование. Коэффициент корреляции между злоупотреблением алкоголем и уровнем образования составил $r=-0,889(m= \pm 0,114, p<0,05)$. Отмечено также, что среди анкетированных пациентов курит 70,4\%, при этом более половины (50,8\%) из числа курящих, считает курение вредной для здоровья привычкой, но не может с ней справиться. Только 3,4\% не считают курение вредным для здоровья.

Проведенное анкетирование показало, что среди обследованных 90,0\% респондентов наркотические вещества и препараты не принимали ни разу. В то же время 7,1\% пациентов пробовали употреблять наркотики, 1,9\% больных употребляют их иногда и каждый сотый регулярно. Все они находились в возрасте до 40 лет.

Среди обследованных пациентов с переломами нижней челюсти 44,2\% страдают избыточной массой тела, что требует коррекции. Только 13,4\% опрошенных контролируют свой вес. Лишний вес и связанное с ним нарушение метаболизма веществ приводят к более поздним срокам консолидации фрагментов костей челюсти, а наличие выраженной жировой клетчатки затрудняет пальпаторную и визуальную диагностику переломов и связанную с ними деформацию челюстно-лицевой области. В ряде случаев подкожно-жировая клетчатка пропитывается кровью, образуются гематомы, которые инфицируются и нагнаиваются. Коэффициент корреляции между указанными признаками составил $r=+0,749(n= \pm 0,114, p<0,05)$. Только 9,8\% больных руководствуются советами врача, выполняют назначения по нормализации своей массь тела, причем таковых больше среди лиц старшего возраста (возраст более 50 лет).

Масса тела может свидетельствовать не только о характере питания пациента, но и о его отношении к физическим нагрузкам. Отмечено, что более половины опрошенных (59,8\%) ведут малоподвижный образ жизни, причем таковых достоверно $(\mathrm{p}<0,05)$ в 2,3 раза больше в возрасте старше 50 лет по сравнению с более молодыми (74,4\% против 31,1\%). В целом три четверти наблюдаемых пациентов имели минимальную медицинскую активность - редко посещали врача при заболеваниях, не участвовали в диспансерных и профилактических осмотрах, не принимали участие в оздоровительных мероприятиях, не считали нужным выполнять назначения врача в полном объеме и др.

\section{РЕЗУЛЬТАТЫ ИССЛЕДОВАНИЯ}

C помощью аппарата PARKELL Digitest 2 (Parkell, CШA) были получены данные о состоянии порога возбудимости кожи в исследуемых зонах, которые иннервирует НАН на подбородке и нижней губе. Определение показателей электроодонтодиагностики не проводили, так как у всех пациентов на момент исследования в полости рта находились назубные металлические шины.

Исследование было проведено в двух группах: группе пациентов с переломом нижней челюсти в области угла, которым были назначены Мексикор и Комбилипен, и группе пациентов, в состав терапии которых не включали данные препараты. Исследование проводили на момент поступления пациента в стационар, на 10-е сутки и на 3240-е сутки, а также по истечении 6 месяцев после травмы.

Установлено, что показатели электровозбудимости кожи в исследованных зонах были выше во 2 и 3 зонах.

При повреждениях легкой степени тяжести НАН средние значения электровозбудимости составляли $55 \pm 1,5$ мкА и $58 \pm 1,5$ мкА. При этом клинические проявления сопровождались чувством «ползания мурашек» в области нижней губы на стороне повреждения, снижением чувствительности кожи на стороне повреждения. При повреждениях средней степени тяжести значения электровозбудимости варьировались от 109,6 \pm 3,1 мКА до 121,9 \pm 3,5 мкА. А при повреждении тяжелой степени тяжести - от 159,5 \pm 4,5 мкА до 168,1 \pm 4,8 мкА, что свидетельствует о большем нарушении чувствительности кожи в данных зонах. Клинические проявления повреждения НАН при повреждениях средней и тяжелой степени тяжести проявлялись полной потерей чувствительности кожи в данных зонах, отмечались выраженный болевой синдром, нарушение работы мимических мышц, нарушение чувствительности слизистой оболочки и зубов на стороне повреждения. У 18,6\% пациентов отмечались незначительные зоны парастезии нижней губы и подбородка с другой стороны, за счет того, что часть ветвей НАН участвуют в иннервации фронтальной группы зубов, образуя общее сплетение.

Результаты исследования показали, что при повреждениях легкой степени тяжести значения электровозбудимости в 1-й и 4-й зонах основной группы пациентов

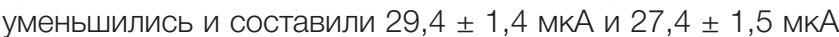
соответственно. Это соответствует показателям электровозбудимости на здоровой стороне. Во 2-й и 3-й зонах отмечалась тенденция к снижению показателей электровозбудимости: они составили 40,1 \pm 4,2 мкА и 42,3 \pm 4,0 мкA в основной группе, в контрольной группе значения

Таблица 1. Показатели электровозбудимости кожи нижней губы во 2-й и 3-й зоне, на момент поступления, в зависимости от степени тяжести повреждения НАН

\begin{tabular}{|c|c|c|c|}
\hline \multirow{2}{*}{ Зона определения } & \multicolumn{3}{|c|}{ Степень тяжести повреждения НАН } \\
\hline & легкая & средняя & тяжелая \\
\hline 2 & $55 \pm 1,5 \mathrm{MK} A$ & $109,6 \pm 3,1 \mathrm{MKA}$ & $159,5 \pm 4,5$ MKA \\
\hline 3 & $58 \pm 1,5 \mathrm{MK} A$ & $121,9 \pm 3,5$ мкA & $168,1 \pm 4,8$ мКА \\
\hline
\end{tabular}


электровозбудимости уменьшились, но в меньшей степени и составили в 1-й зоне 35,1 \pm 1,4 мкA, во 2-й зоне 49,6 \pm 4,6 мкA, в 3-й зоне - 50,8 \pm 4,6 мкA, 4-й зоне $36,2 \pm 1,6$ MKA.

При повреждениях средней и тяжелой степени тяжести в основной группе пациентов также наблюдалось снижение значений электровозбудимости кожи на стороне повреждения. Эти показатели были в 1,2-1,3 раза ниже по сравнению с контрольной группой.

В результате анализа данных электровозбудимости кожи в исследованных зонах видно, что при поражениях легкой степени тяжести показатели в основной и контрольной группах равны значениям электровозбудимости на здоровой стороне. Лишь у 15\% пациентов контрольной группы чувство «ползания мурашек» сохранилось, у всех остальных пациентов контрольной и основной групп, клинические симптомы повреждения НАН купировались.

При повреждениях средней тяжести наиболее высокие показатели электровозбудимости отмечались во 2-й и 3-й зонах. В среднем они составили 40,5 \pm 3,9 мкА и 59,7 \pm 3,7 мкА в основной группе и более высокие показатели были в контрольной группе - 65,1 \pm 5,4 мкА и 85,7 \pm 5,1 мкА. Клинические симптомы характеризовались уменьшением зоны парестезии у пациентов основной группы по сравнению с пациентами контрольной группы. У 25\% исследуемых пациентов контрольной группы площадь парестезии сохранялась на прежнем уровне.

При повреждениях тяжелой степени тяжести значения показателей электровозбудимости кожи в исследуемых квадрантах в основной группе были в 1,3-1,4 раза меньше, чем значения электровозбудимости у пациентов контрольной группы. У $73 \%$ пациентов контрольной группы, клинические симптомы сохранялись на прежнем уровне, тогда как в основной группе отмечалась положительная динамика в виде уменьшения площади парестезии, снижения болевого синдрома. Согласно результатам измерений электровозбудимости, проведенным на 3240-е сутки лечения, можно сделать вывод, что во всех четырех зонах значения электровозбудимости понизились у пациентов, в состав терапии которых, входили препараты Комбилипен и Мексикор. Выбор препаратов был не случайным: согласно приказу Министерства Здравоохранения №1497н от 24.12.2012 г. «Лечение пациентов при поражении лицевого нерва» В комплексной терапии рекомендовано использовать витамины В1 и В6, В12, а также на основании проведенных многочисленных клинических исследований, которые отражены в отечественной и зарубежной литературе, применение антиоксидантных препаратов играет важнейшую роль в лечении травматических повреждений периферических нервов [18, 19].

Реабилитация больных с переломами нижней челюсти включала проведение социально-психологических и медицинских мероприятий. Полученные результаты показали, что среди пациентов только половина $(47,7 \%)$ выполнили все лечебные мероприятия в полном объеме, 32,7\% - не выполняли рекомендации врача, а 19,6\% выполнили назначения не в полном объеме.

Среди причин, препятствующих выполнению медицинской реабилитации, пациенты называли такие, как отсутствие положительного эффекта от назначений (49,3 случаев), очереди в отделениях больницы и поликлиниках (41,2 случаев), неприятные и болезненные ощущения во время выполнения медицинских процедур (38,7 случаев), отсутствие материальных средств для выполнения предложенных методов лечения (37,6 случаев), отсутствие мотивации для выполнения рекомендаций $(28,4$ случаев), отсутствие доверия к медицинскому персоналу (23,0 случая) (в расчете на 100 опрошенных больных). Установлено, что почти половина опрошенных из числа лиц, не выполнивших программу медицинской реабилитации в полном объеме, назвали от 2 до 3 причин, которые, по их мнению, препятствовали проведению полного курса лечения.

\section{ОБСУЖДЕНИЕ РЕЗУЛЬТАТОВ}

Показатели электровозбудимости кожи в области иннервации НАН в зоне 2 и 3 на момент поступления составили: при поражениях легкой степени тяжести 55,5 \pm 1,5 мкА и $58 \pm$ 1,5 мкА; при поражениях средней степени тяжести - 109,6 \pm 3,1 мкА и 121,9 \pm 3,5 мкA, при поражениях тяжелой степени тяжести - 159,5 \pm 4,5 мкА и 168,1 \pm 4,8 мкА. Через 10 дней после травмы показатели в основной группе уменьшились в 1,2-1,3 раза, по сравнению с показателями в контрольной группе. На 32-40-е сутки значения электровозбудимости составили: при поражениях средней тяжести 40,5 \pm 3,9 мкА и $59,7 \pm 3,7$ мкА, а в контрольной группе - 65,1 \pm 5,4 мкA и 85,7 \pm 5,1 мкА; при поражениях тяжелой степени значения были в 1,3-1,4 раза меньше, чем в контрольной группе. Отмечалось сохранение клинической симптоматики у 73\% пациентов контрольной группе на прежнем уровне, тогда как в основной группе наблюдалась положительная динамика в виде уменьшения площади парестезии, снижения болевого синдрома.

Результаты исследования показали, что у пациентов с поражениями легкой и средней степенями тяжести повреждения НАН показатели электровозбудимости не превышали значений нормы. Клинические симптомы травмы НАН, такие как чувство онемения кожи нижней губы, боль при пальпации нижней губы и нарушение чувствительности слизистой на стороне повреждения, полностью купировались.

При повреждениях тяжелой степени тяжести в основной группе пациентов показатели электровозбудимости во всех исследуемых зонах тоже не превышали показатели нормы. Однако в контрольной группе у 12 пациентов показания электровозбудимости были повышены во 2-й и Зй зонах и составили 45,1 \pm 3,2 мКА и 43,2 \pm 3,1 мкA соответственно. Это характерно для клинической симптоматики, которая проявлялась, чувством онемения и ползания «мурашек» во 2-й и 3-й зонах пациентов контрольной группы.

На основании определения показателей электровозбудимости кожи подбородка и нижней губы на стороне повреждения было выявлено, что площадь участка парестезии в области нижней губы, угла рта, кожи подбородка, десен на стороне повреждения, к 32-40 дню уменьшилась у 103 пациентов по сравнению с контрольной группой и захватывала только две зоны - 2 и З. Благодаря влиянию Мексикора на микроциркуляцию отек мягких тканей на стороне повреждения у 74 пациентов, принимавших в составе комплексной терапии данный препарат, на 3-й день лечения был значительно меньше выражен.

Важнейшим направлением явилась санитарно-просветительная работа по внедрению в повседневную жизнедеятельность пациентов элементов здорового образа жизни. В итоге проведенного исследования было выявлено, что ведущей ролью в формировании неблагоприятных показателей здоровья у исследуемых является низкий 
уровень медицинской активности большей части обследованных. Рекомендации по коррекции медицинской активности были направлены на внедрение элементов здорового образа жизни и изменение медицинского поведения среди пациентов с травмой НАН. Это позволило увеличить удельный вес пациентов, внедривших правила рационального питания (с 13,6\% до 36,2\%), нормализовавших сон (с 16,1\% до 30,0\%), повысивших физическую активность (с 12,6\% до 23,2\%), отказавшихся от курения $(11,0 \%)$

\section{ВЫВОДЫ}

На основании измерений электровозбудимости, проведенных на 32-40-е сутки лечения, можно сделать вывод, что во всех четырех зонах при повреждении средней и тяжелой степеней тяжести значения электровозбудимости понизились у пациентов, в состав терапии которых входили препараты Комбилипен и Мексикор.

\section{Литература}

1. Копецкий И. С., Притыко А. Г., Полунина Н. В., Насибуллин А. М. Травматизм челюстно-лицевой области среди населения. РMЖ. 2009; 6: 3-6.

2. Celeste RK. Illegal dmg use is associated with postoperative complications in persons with mandibular fractures. J Evid Based Dent Pract. 2009; 9: 227-8.

3. Корж Г. М. Диагностика и лечение повреждений нижнего альвеолярного нерва при переломах нижней челюсти и стоматологических манипуляциях [диссертация]. Смоленск: 1989

4. Тимофеев А. А., Леснухин В. Л. Изучение состояния нижнего альвеолярного нерва при повреждениях нижней челюсти в динамике проводимого лечения. Часть 1. Современная стоматология. 2009; 3: 109-15.

5. Морозова М. Н., Шаблий Д. Н., Джерелей А. А. К вопросу о диагностике степени тяжести травматического неврита нижнего альвеолярного нерва. Вестник проблем биологии и медицины. 2013; 2 (100): 314-8.

6. Скуридина, Е. П. Клинико-диагностические критерии невралгии тройничного нерва. [диссертация]. М.: 2006.

7. Левенец А. А., Григорьян А. С. К патогенезу посттравматических десормаций нижней челюсти растущего организма. Стоматология. 2000; 1: 20-5.

8. Baker B, Gibbons S, Woods M. Intra-alveolar distraction osteogenesis in preparation fordental implant placement combined with orthodontic/orthognathic surgical treatment: A case report. Australian Dental Journal. 2003; 48: 65-8.

9. Копылов А. В., Сирак С. В., Копылова И. А. и др.. Комплексное лечение одонтогенных травм нижнего альвеолярного нерва. Современные проблемы науки и образования. 2013; 4 URL: www.science-education.ru/111-10132.

10. Горбонос И. А. Осложнения при остеосинтезе переломов

\section{References}

1. Kopetskiy IS, Prityko AG, Polunina NV, Nasibullin AM. Travmatizm chelyustno-litsevoy oblasti sredi naseleniya. RMZh. 2009; 6: 3-6.

2. Celeste RK. Illegal dmg use is associated with postoperative complications in persons with mandibular fractures. J Evid Based Dent Pract. 2009; 9: 227-8.

3. Korzh GM. Diagnostika i lechenie povrezhdeniy nizhnego al'veolyarnogo nerva pri perelomakh nizhney chelyusti i stomatologicheskikh manipulyatsiyakh: avtoref [dissertatsiya]. Smolensk: 1989.
Площадь парестезии у пациентов основной группы также уменьшилась и захватывала только 2 и 3 зоны, тогда как в контрольной группе она распространялась на 1, 2 и 3 зоны. На основании этого можно заключить, что применение Комбилипена и Мексикора в комплексном лечении больных с повреждением НАН позволяет ускорить регенерацию поврежденного нервного волокна и уменьшить клинические симптомы повреждения НАН.

Проведение реабилитационных мероприятий по повышению качества жизни и медицинской активности положительно способствовало изменению характера медицинского поведения, нормализации психоэмоционального фона, формированию здорового образа жизни. С увеличением доли больных, вовлеченных в различные виды реабилитации, увеличилась количество пациентов, считающих необходимым руководствоваться назначениями врача на 31,2\%. Это привело к увеличению в 2,9 раза числа больных с повреждениями НАН, восстановивших функции челюстно-лицевой области в полном объеме. нижней челюсти и их профилактика [диссертация]. Новосибирск: 2007.

11. Боднева С. Л., Пузин М. Н., Кипарисова Е. С. Комплексная терапия одонтогенного неврита луночковых нервов. Клиническая неврология. 2010; 1: 14-7.

12. Иващенко Н. И., Ипполитов В. П. Остеосинтез в лечении тяжелых сочетанных черепно-лицевых травм у юношей. Клиническая стоматология. 2007; 3: 56-9.

13. Jungel P. Parasthesia of infraorbital nerve following fractura of zygomatic complex. J Oral Maxillofac Surg. 1987; 16 (3): 362-7.

14. Полунин В. С., Дубровин М. С., Копецкий И. С. Медикосоциальная характеристика больных с повреждениями челюстно-лицевой области. Вестник Росздравнадзора. 2013; 2: 46-9.

15. Копецкий И. С., Насибуллин А. М. Медико-социальная характеристика больных с тяжелыми сочетанными повреждениями средней зоны лица и особенности оказания им медицинской помощи в условиях реанимационного отделения. РМЖ. 2012; 2: 3-7.

16. Григорьянц Л. А. Сирак С. В., Копылова И. А., Елизаров А. В. Хирургическое лечение одонтогенных компрессионных травм нижнего альвеолярного нерва после эндодонтических вмешательств. Эндодонтия today. 2013; 4: 53-8.

17. Сирак С. В. Клинико-анатомическое обоснование лечения и профилактики травм нижнеальвеолярного нерва, вызванных выведением пломбировочного материала в нижнечелюстной канал [диссертация]. М.: 2006.

18. Белоусов А. Е. Пластическая, реконструктивная и эстетическая хирургия. СПб.: Гиппократ; 1998. 774 с.

19. Kurtoglu Z. et. al. Effect of trapidil after crush injury to a peripheral nerve. Acta Med Okayama. 2005; 59 (2): 37-44.
4. Timofeev AA, Lesnukhin VL. Izuchenie sostoyaniya nizhnego al'veolyarnogo nerva pri povrezhdeniyakh nizhney chelyusti $v$ dinamike provodimogo lecheniya. Chast' 1. Sovremennaya stomatologiya. 2009; 3: 109-15.

5. Morozova MN, Shabliy DN, Dzhereley AA. K voprosu o diagnostike stepeni tyazhesti travmaticheskogo nevrita nizhnego al'veolyarnogo nerva. Vestnik problem biologii i meditsiny. 2013; 2 (100): 314-18.

6. Skuridina EP. Kliniko-diagnosticheskie kriterii nevralgii 
troynichnogo nerva [dissertatsiya]. M.: 2006.

7. Levenets AA, Grigor'yan AS. K patogenezu posttravmaticheskikh deformatsiy nizhney chelyusti rastushchego organizma. Stomatologiya. 2000; 1: 20-5.

8. Baker B, Gibbons S, Woods M. Intra-alveolar distraction osteogenesis in preparation for dental implant placement combined with orthodontic/orthognathic surgical treatment: $A$ case report. Australian Dental Journal. 2003; 48: 65-8.

9. Kopylov AV, Sirak SV, Kopylova IA i dr. Kompleksnoe lechenie odontogennykh travm nizhnego al'veolyarnogo nerva. Sovremennye problemy nauki i obrazovaniya. 2013; 4. URL: www.science-education.ru/111-10132.

10. Gorbonos IA. Oslozhneniya pri osteosinteze perelomov nizhney chelyusti i ikh profilaktika [dissertatsiya]. Novosibirsk: 2007.

11. Bodneva SL, Puzin MN, Kiparisova ES i dr. Kopmleksnaya terapiya odontogennogo nevrita lunochkovykh nervov. Klinicheskaya nevrologiya. 2010; 1: 14-7.

12. Ivashchenko NI, Ippolitov VP. Osteosintez v lechenii tyazhelykh sochetannykh cherepno-litsevykh travm u yunoshey. Klinicheskaya stomatologiya. 2007; 3: 56-9.

13. Jungel P. Parasthesia of infraorbital nerve following fractura of zygomatic complex. J Oral Maxillofac Surg. 1987; 16 (3): 362-7.

14. Polunin VS, Dubrovin MS, Kopetskiy IS. Mediko-sotsial'naya kharakteristika bol'nykh s povrezhdeniyami chelyustno-litsevoy oblasti. Vestnik Roszdravnadzora. 2013; 2: 46-9.

15. Kopetskiy IS, Nasibullin AM. Mediko-sotsial'naya kharakteristika bol'nykh s tyazhelymi sochetannymi povrezhdeniyami sredney zony litsa i osobennosti okazaniya im meditsinskoy pomoshchi v usloviyakh reanimatsionnogo otdeleniya. RMZh. 2012; 2: 3-7.

16. Grigoryants LA, Sirak SV, Kopylova IA, Elizarov AV. Khirurgicheskoe lechenie odontogennykh kompressionnykh travm nizhnego al'veolyarnogo nerva posle endodonticheskikh vmeshatel'stv. Endodontiya today. 2013; 4: 53-8.

17. Sirak SV. Kliniko-anatomicheskoe obosnovanie lecheniya i profilaktiki travm nizhneal'veolyarnogo nerva, vyzvannykh vyvedeniem plombirovochnogo materiala $v$ nizhnechelyustnoy kanal [dissertatsiya]. M.: 2006.

18. Belousov AE. Plasticheskaya, rekonstruktivnaya i esteticheskaya khirurgiya. SPb.: Gippokrat, 1998. 774 p.

19. Kurtoglu $Z$ et al. Effect of trapidil after crush injury to a peripheral nerve. Acta Med Okayama. 2005; 59 (2): 37-44. 